Research Paper

\title{
Bisphosphonate Modulation of the Gene Expression of Different Markers Involved in Osteoblast Physiology: Possible Implications in Bisphosphonate-Related Osteonecrosis of the Jaw
}

Francisco Javier Manzano-Moreno ${ }^{1,2^{*}}$, Javier Ramos-Torrecillas ${ }^{2,3^{*}}$, Lucia Melguizo-Rodríguez 2,3, Rebeca Illescas-Montes 2,4 , Concepción Ruiz ${ }^{2,3,5 凶}$, Olga García-Martínez ${ }^{2,3}$

1. Biomedical Group (BIO277), Department of Stomatology, School of Dentistry, University of Granada, Spain.

2. Instituto Investigación Biosanitaria, ibs.Granada (Spain).

3. Biomedical Group (BIO277), Department of Nursing, Faculty of Health Sciences. University of Granada, Spain.

4. Biomedical Group (BIO277), Department of Nursing, Faculty of Nursing, Melilla. University of Granada, Spain.

5. Institute of Neuroscience, Parque Tecnológico Ciencias de la Salud, Armilla (Granada), University of Granada, Spain.

*Authors Francisco Javier Manzano-Moreno and Javier Ramos-Torrecillas contributed equally to this study.

$\triangle$ Corresponding author: Concepcion Ruiz, Faculty of Health Sciences. University of Granada, Spain. Avda. De la Ilustración 60, 18016-Granada, Spain. Telephone: +34-958243497; Telefax: +34-958242894; e-mail: crr@ugr.es

(C) Ivyspring International Publisher. This is an open access article distributed under the terms of the Creative Commons Attribution (CC BY-NC) license (https://creativecommons.org/licenses/by-nc/4.0/). See http://ivyspring.com/terms for full terms and conditions.

Received: 2017.08.31; Accepted: 2018.01.05; Published: 2018.02.12

\begin{abstract}
The aim of the present study was to elucidate the role of osteoblasts in bisphosphonates-related osteonecrosis of the jaw (BRONJ). The specific objective was to evaluate the effect on osteoblasts of two nitrogen-containing BPs (zoledronate and alendronate) and one non-nitrogen-containing BP (clodronate) by analyzing modulations in their expression of genes essential for osteoblast physiology. Real-time polymerase chain reaction (RT-PCR) was used to study the effects of zoledronate, alendronate, and clodronate at doses of $10^{-5}, 10^{-7}$, or $10^{-9} \mathrm{M}$ on the expression of Runx-2, OSX, ALP, OSC, OPG, RANKL, Col-I, BMP-2, BMP-7, TGF- 1 1, VEGF, TGF- $\beta R 1$, TGF- $\beta R 2$, and TGF- $\beta R 3$ by primary human osteoblasts (HOBs) and MG-63 osteosarcoma cells. Expression of these markers was found to be dose-dependent, with no substantive differences between these cell lines. In general, results demonstrated a significant increase in TFG- $\beta 1$, TGF- $\beta R 1$, TGF- $\beta R 2$, TGF- $\beta R 3$, and VEGF expressions and a significant reduction in RUNX-2, Col-1, OSX, OSC, BMP-2, BMP-7, ALP, and RANKL expressions, while OPG expression varied according to the dose and cell line. The results of this in vitro study of HOBS and MG-63 cell lines indicate that low BP doses can significantly affect the expression of genes essential for osteoblast growth and differentiation and of genes involved in regulating osteoblast-osteoclast interaction, possibly by increasing TGF- $\beta 1$ production. These findings suggest that osteoblasts may play an important role in BRONJ development, without ruling out other factors.
\end{abstract}

Key words: bisphosphonates, osteoblast, BRONJ, gene expression, TGF- $\beta 1$

\section{Introduction}

Bisphosphonates (BPs) are the first-line treatment for osteoporosis, Paget's disease, multiple myeloma, and malignant hypercalcemia, among other bone disorders [1]. Randomized controlled clinical trials have demonstrated the effectiveness of these drugs, but they have also been implicated in the development of BP-related osteonecrosis of the jaw (BRONJ) $[2,3]$.

Among other possible etiologies, BRONJ has been associated with reduced bone turnover and consequent accumulation of microfractures, avascular necrosis due to anti-angiogenic effects, and impaired 
viability of fibroblasts and oral keratinocytes [2, 4]. Our group previously demonstrated that high doses of BPs exert toxic effects on osteoblasts [5] and that low doses of these drugs reduce their differentiation capacity [6, 7].

There are two major types of BPs, those that contain nitrogen and those that do not, with distinct molecular action mechanisms and different therapeutic indications [8]. BRONJ development has been related to both nitrogen-containing (e.g. alendronate, zoledronate, or ibandronate) and non-nitrogen-containing (e.g., clodronate) BPs $[9,10]$.

Osteoblasts play an essential role in bone physiology through their participation in bone formation and turnover and in bone tissue repair. The maturation and function of this cell population is highly complex, involving autocrine, paracrine, and endocrine factors [11].

Despite 25 years of clinical research on BPs, the mechanism of their action on osteoclasts and osteoblasts remains unclear, although evidence has emerged that BPs may interact with them by modulating the expression of osteoblast-synthesized osteoclastogenic factors [12]. Adequate bone metabolism requires the correct functioning of the osteoblastosteoclast relationship. Among other mechanisms, this process involves the complex formed by the receptor activator of nuclear factor kappa-B ligand (RANKL) and osteoprotegerin (OPG) and the release of matrix-derived osteogenic growth factors, e.g., transforming growth factor $\beta 1$ (TGF- $\beta 1$ ) [13-16], all of which can be altered by BP administration.

The objective of this study was to evaluate the effect of two nitrogen-containing BPs (zoledronate and alendronate) and one non-nitrogen-containing BP (clodronate) on osteoblasts by analyzing their gene expression of bone morphogenetic protein 2 (BMP-2), and BMP-7, vascular endothelial growth factor (VEGF), and TGF- $\beta 1$ and TGF- $\beta$ receptors (TGF- $\beta$ R1, TGF- $\beta$ R2; TGF- $\beta$ R3). The role of the osteoblast in BRONJ development was also explored by analyzing the effects of these BPs on the expression of the following osteoblast differentiation markers: runt-related transcription factor 2 (Runx-2), alkaline phosphatase (ALP), type I collagen (Col-I), osterix (OSX), OPG, RANKL, and osteocalcin (OSC).

\section{Material and Methods}

\section{Osteoblast isolation and culture}

Osteoblasts were isolated, characterized, and cultured from bone sections obtained in the course of mandibular surgery from three Caucasian patients (2 female and 1 male) aged between 20 and 30 yrs. The independently processed sections were thoroughly washed in phosphate-buffered saline (PBS, pH 7.4) to remove the marrow and were then seeded onto culture dishes (Falcon Labware, Oxford, UK) in Dulbecco's modified Eagle medium (Sigma Chemical Co., St. Louis, MO) containing $20 \%$ fetal calf serum (FCS). Cultures were kept at $37^{\circ} \mathrm{C}$ in a humidified atmosphere of $95 \%$ air and $5 \% \mathrm{CO}_{2}$. Confluent monolayers were obtained after 3-6 weeks. These cultures allowed three highly pure human osteoblast (HOB) cell lines to be obtained (one per patient), with proliferating osteoblastic cells overgrowing other possible contaminant cells. Cells were detached from the culture flask with a solution of $0.05 \%$ trypsin and $0.02 \%$ ethylenediaminetetraacetic acid (EDTA), and they were washed and suspended in complete culture medium with $20 \%$ FCS. Finally, the cells were characterized as described by Reyes-Botella et al. [17] and García-Martínez et al. [18]

Human MG-63 osteosarcoma cell line (MG-63) was purchased from American Type Cultures Collection (ATCC, Manassas, VA) and maintained as described above with 10\% FCS. This cell line is commonly used as an osteoblast model because it shares the same characteristics with osteoblasts.

All procedures performed in this study involving human participants were in accordance with the ethical standards of the ethical committee of the University of Granada (reference no. 721) and with the 1964 Helsinki declaration and its later amendments or comparable ethical standards.

\section{Treatments}

HOB and MG-63 cell lines were treated with two nitrogen-containing BPs, zoledronate (Sigma-Aldrich, St. Louis, MO) and alendronate (Sigma), and one non-nitrogen-containing $\mathrm{BP}$, clodronate (SigmaAldrich) at doses of $10^{-5}, 10^{-7}$, or $10^{-9} \mathrm{M}$, which are within the therapeutic dose range [7], for $24 \mathrm{~h}$.

\section{RNA extraction and cDNA synthesis (reverse transcription)}

After $24 \mathrm{~h}$ of culture with BP treatment (untreated cells served as controls), cells were detached from the culture flask using $0.05 \%$ trypsin-EDTA solution (Sigma) and individually harvested. mRNA was extracted using a silicate gel technique in the QiagenRNeasy extraction kit (Qiagen Inc., Hilden, Germany), which includes a DNAse digestion step. The amount of extracted mRNA was measured by UV spectrophotometry at $260 \mathrm{~nm}$ (Eppendorf AG, Hamburg, Germany), and contamination with proteins was determined according to the 260/280 ratio. An equal amount of RNA ( $1 \mu \mathrm{g}$ of total RNA in $40 \mu \mathrm{l}$ of total volume) was reverse-transcribed to cDNA and amplified by PCR 
using the iScript ${ }^{\mathrm{TM}}$ cDNA Synthesis Kit (Bio-Rad laboratories, Hercules, CA, USA), following the manufacturer`s instructions.

\section{Real-time polymerase chain reaction (RT-PCR)}

Primers (Table 1) were designed using NCBInucleotide library and Primer3-design to detect mRNA of Runx-2, OSX, ALP, OSC, OPG, RANKL, Col-I, BMP-2, BMP-7, TGF- $\beta 1$, VEGF, TGF- $\beta$ R1, TGF$\beta R 2$, and TGF- $\beta$ R3. All were matched to the mRNA sequences of target genes (NCBI Blast software).

Final results were normalized using ubiquitin $C$ (UBC), peptidylprolyl isomerase A (PPIA), and ribosomal protein S13 (RPS13) as stable housekeeping genes $[19,20]$.

Quantitative RT-PCR (q-RT-PCR) was conducted using the SsoFast ${ }^{\mathrm{TM}}$ EvaGreen ${ }^{\circledR}$ Supermix Kit (Bio-Rad laboratories) and following the manufacturer`s instructions. Samples were amplified in 96-well microplates in an IQ5-Cycler (Bio-Rad laboratories) at a specific annealing temperature for each gene, ranging from 60 to $65{ }^{\circ} \mathrm{C}$, and at an elongation temperature of $72{ }^{\circ} \mathrm{C}$ over 40 cycles. PCR reactions were carried out in a final volume of $20 \mu \mathrm{L}$, with $5 \mu \mathrm{L}$ of cDNA sample and $2 \mu \mathrm{L}$ of each primer. $\mathrm{Ct}$ values were plotted against log cDNA dilution to construct standard curves for each target gene. After each RT-PCR, a melting profile was created and agarose gel electrophoresis was conducted in each sample to rule out nonspecific PCR products and primer dimers. The comparative $\mathrm{Ct}$ method was employed for the relative quantification of gene expression. The mRNA concentration for each gene was expressed as ng of mRNA per average ng of housekeeping mRNAs. The cDNA from individual cell experiments was analyzed in triplicate RT-PCR studies.

\section{Statistical analysis}

SPSS 22.0 (IBM, Chicago, IL) was used for the data analyses. mRNA levels were expressed as means \pm standard deviation (SD). A two-tailed unpaired Student's $t$ test was used for comparisons. At least three experiments were performed for all assays. $\mathrm{P}<$ 0.05 was considered statistically significant in all tests.

\section{Results}

\section{Effect of BPs on gene expression of TGF- $\beta 1$ and its receptors (TGF- $\beta$ R1, TGF- $\beta$ R2, and TGF- $\beta$ R3)}

Figure 1 displays q-RT-PCR results for the gene expression of TGF- $\beta 1$ and its receptors (TGF- $\beta$ R1, TGF- $\beta$ R2, and TGF- $\beta$ R3). In the HOB cell line, TGF- $\beta 1$ expression was significantly decreased versus the control group after $24 \mathrm{~h}$ of treatment with the highest dose of alendronate $\left(10^{-5} \mathrm{M}\right)$ but not with zoledronate or clodronate at this dose. TGF- $\beta 1$ expression was significantly increased in both cell lines at the lowest doses $\left(10^{-7}\right.$ and $\left.10^{-9} \mathrm{M}\right)$ of each BP. Results in figure 1 also show that the BP treatment of both cell lines produced a significantly increase in TGF- $\beta$ R1 and TGF- $\beta$ R2 expressions that was directly proportional to the reduction in dose. However, the expression of TGF- $\beta$ R3 varied as a function of the BP, dose, and cell line, generally showing a significant increase at doses of $10^{-7}$ and $10^{-9} \mathrm{M}$ in the MG-63 cell line and a significant decrease versus controls at the highest dose $\left(10^{-9} \mathrm{M}\right)$; in contrast, the only significant change in $\mathrm{HOB}$ cells was a post-treatment increase in TGF- $\beta$ R3 expression at a dose of $10^{-9} \mathrm{M}$.

Table 1. Primer sequences for the amplification of cDNA by real-time PCR

\begin{tabular}{|c|c|c|c|}
\hline Gene & Sense Primer & Antisense Primer & Amplicon (bp) \\
\hline TGF- $\beta 1$ & 5’-TGAACCGGCCTTTCCTGCTTCTCATG-3' & 5'-GCGGAAGTCAATGTACAGCTGCCGC-3' & 152 \\
\hline TGF- $\beta$ R1 & 5'-ACTGGCAGCTGTCATTGCTGGACCAG-3' & 5'-CTGAGCCAGAACCTGACGTTGTCATATCA-3' & 201 \\
\hline TGF- $\beta$ R2 & 5'-GGCTCAACCACCAGGGCATCCAGAT-3' & 5’-CTCCCCGAGAGCCTGTCCAGATGCT-3’' & 139 \\
\hline TGF- $\beta$ R3 & 5’-ACCGTGATGGGCATTGCGTTTGCA-3’' & 5'-GTGCTCTGCGTGCTGCCGATGCTGT-3’' & 173 \\
\hline RUNX-2 & 5’-TGGTTAATCTCCGCAGGTCAC-3’’ & 5’-ACTGTGCTGAAGAGGCTGTTTG-3’' & 143 \\
\hline $\begin{array}{l}\text { VEGF } \\
\text { OSX }\end{array}$ & $\begin{array}{l}\text { 5'-CCTTGCTGCTCTACCTCCAC-3' } \\
\text { 5'-TGCCTAGAAGCCCTGAGAAA-3' }\end{array}$ & $\begin{array}{l}\text { 5'-CACACAGGATGGCTTGAAGA-3' } \\
\text { 5'-TTTAACTTGGGGCCTTGAGA-3' }\end{array}$ & $\begin{array}{l}197 \\
205\end{array}$ \\
\hline BMP-2 & 5'-TCGAAATTCCCCGTGACCAG-3' & 5'-CCACTTCCACCACGAATCCA-3' & 142 \\
\hline BMP-7 & 5'-CTGGTCTTTGTCTGCAGTGG-3' & 5'-GTACCCCTCAACAAGGCTTC-3' & 202 \\
\hline ALP & 5'-CCAACGTGGCTAAGAATGTCATC-3' & 5'-TGGGCATTGGTGTTGTACGTC-3' & 175 \\
\hline COL-I & 5’-AGAACTGGTACATCAGCAAG-3' & 5'-GAGTTTACAGGAAGCAGACA-3' & 471 \\
\hline OSC & 5'-CCATGAGAGCCCTCACACTCC-3' & 5'-GGTCAGCCAACTCGTCACAGTC-3' & 258 \\
\hline $\begin{array}{l}\text { OPG } \\
\text { RANKL }\end{array}$ & $\begin{array}{l}\text { 5'-ATGCAACACAGCACAACATA-3' } \\
\text { 5'-ATACCCTGATGAAAGGAGGA-3' }\end{array}$ & $\begin{array}{l}\text { 5'-GTTGCCGTTTTATCCTCTCT-3' } \\
\text { 5'-GGGGCTCAATCTATATCTCG-3' }\end{array}$ & $\begin{array}{l}198 \\
202\end{array}$ \\
\hline UBC & 5'-TGGGATGCAAATCTTCGTGAAGACCCTGAC-3' & 5'-ACCAAGTGCAGAGTGGACTCTTTCTGGATG-3' & 213 \\
\hline PPIA & 5'-CCATGGCAAATGCTGGACCCAACACAAATG-3' & 5'-TCCTGAGCTACAGAAGGAATGATCTGGTGG-3' & 256 \\
\hline RPS13 & 5'-GGTGTTGCACAAGTACGTTTTGTGACAGGC-3' & 5'-TCATATTTCCAATTGGGAGGGAGGACTCGC-3’ & 251 \\
\hline
\end{tabular}


A $\quad$ TGFB1

B TGFB-R1

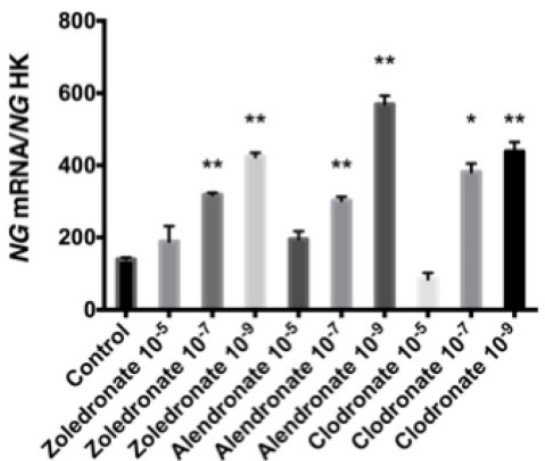

C

TGFB-R2

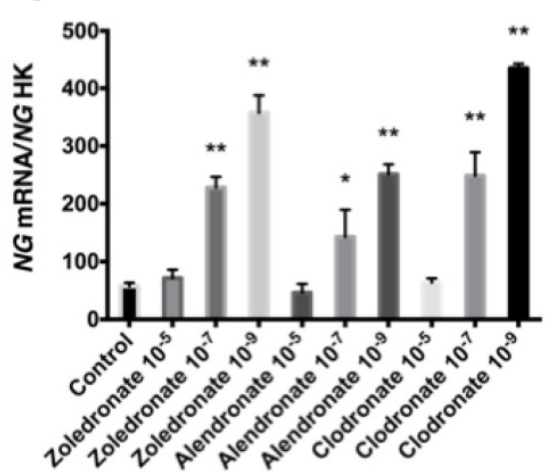

E

TGFB1

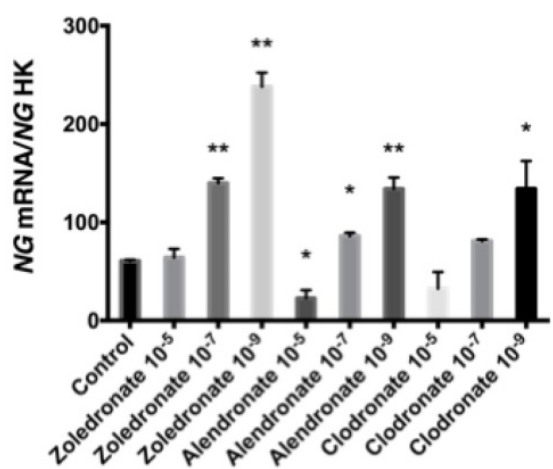

G

TGFB-R2

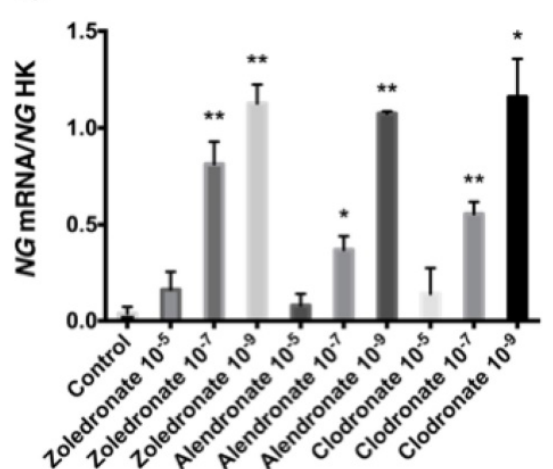

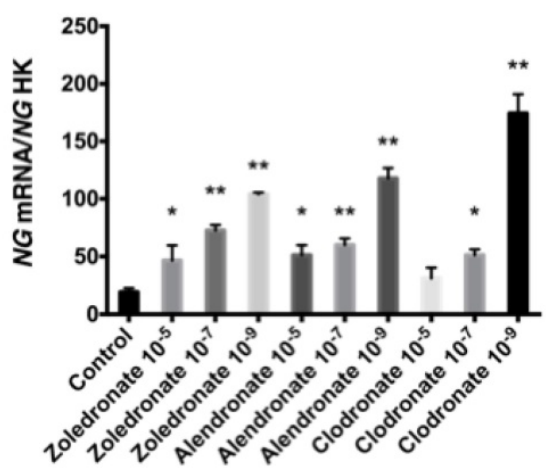

D

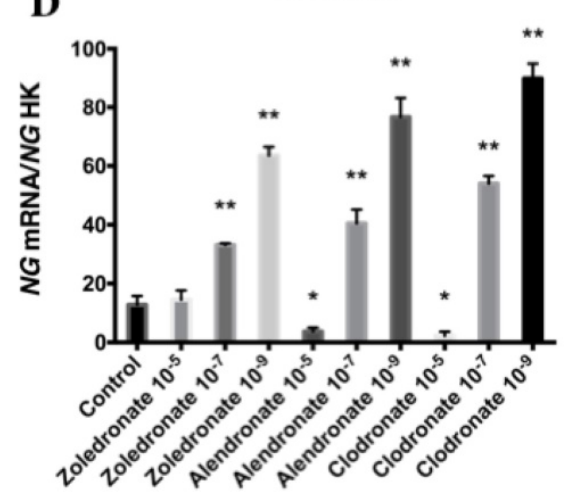

F

TGFB-R1

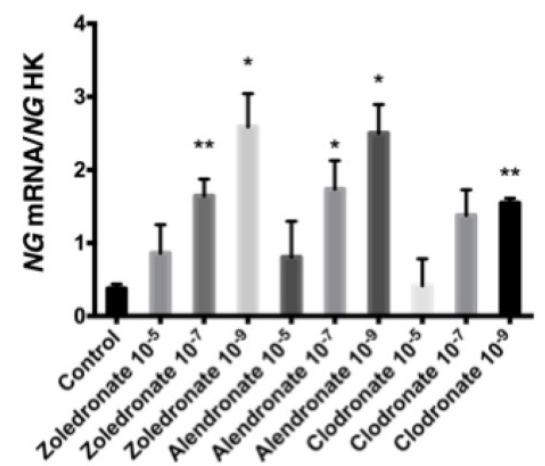

H

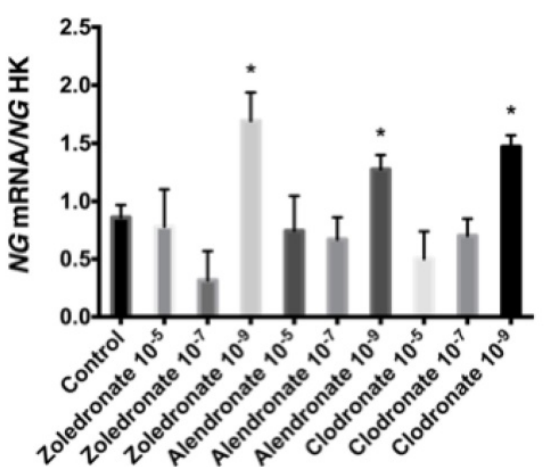

Figure 1. Expression of osteoblast genes (TFG- $\beta 1$, TFG $\beta R 1$, TFG $\beta R 2$, and TFG $\beta R 3$ ) treated for $24 \mathrm{~h}$ with zoledronate, alendronate or clodronate at doses of 10-5, 10-7, or 10-9 M. MG-63 cell line (A,B.C,D); HOB (E,F,G,H). Data are expressed as ng of mRNA per average ng of housekeeping mRNAs $\pm S D$. $* p<0.05$, **p $<0.001$ 


\section{Effect of BPs on gene expression of RANKL-OPG complex}

Figure 2 depicts q-RT-PCR results for the gene expression of RANKL and OPG. In the HOB cell line, RANKL expression was significantly decreased at higher doses of each BP, with a more marked reduction at $10^{-5} \mathrm{M}$. This decrease was also observed in the MG-63 cell line, although it varied according to the $\mathrm{BP}$ and dose used.

In the HOB cell line, OPG expression was significantly reduced at a $\mathrm{BP}$ dose of $10^{-5} \mathrm{M}$ but was not affected at lower doses $\left(10^{-7}\right.$ and $\left.10^{-9} \mathrm{M}\right)$. In the MG-63 cell line, however, OPG expression was significantly increased by treatment with all three BPs (zoledronate, alendronate, and clodronate) at all three doses $\left(10^{-5}, 10^{-7}\right.$, and $\left.10^{-9} \mathrm{M}\right)$.

Effect of BPs on the gene expression of Runx2, ALP, Col-I, OSX, and OSC

Figures 3 and 4 reports the q-RT-PCR results for the expression of osteoblast differentiation makers
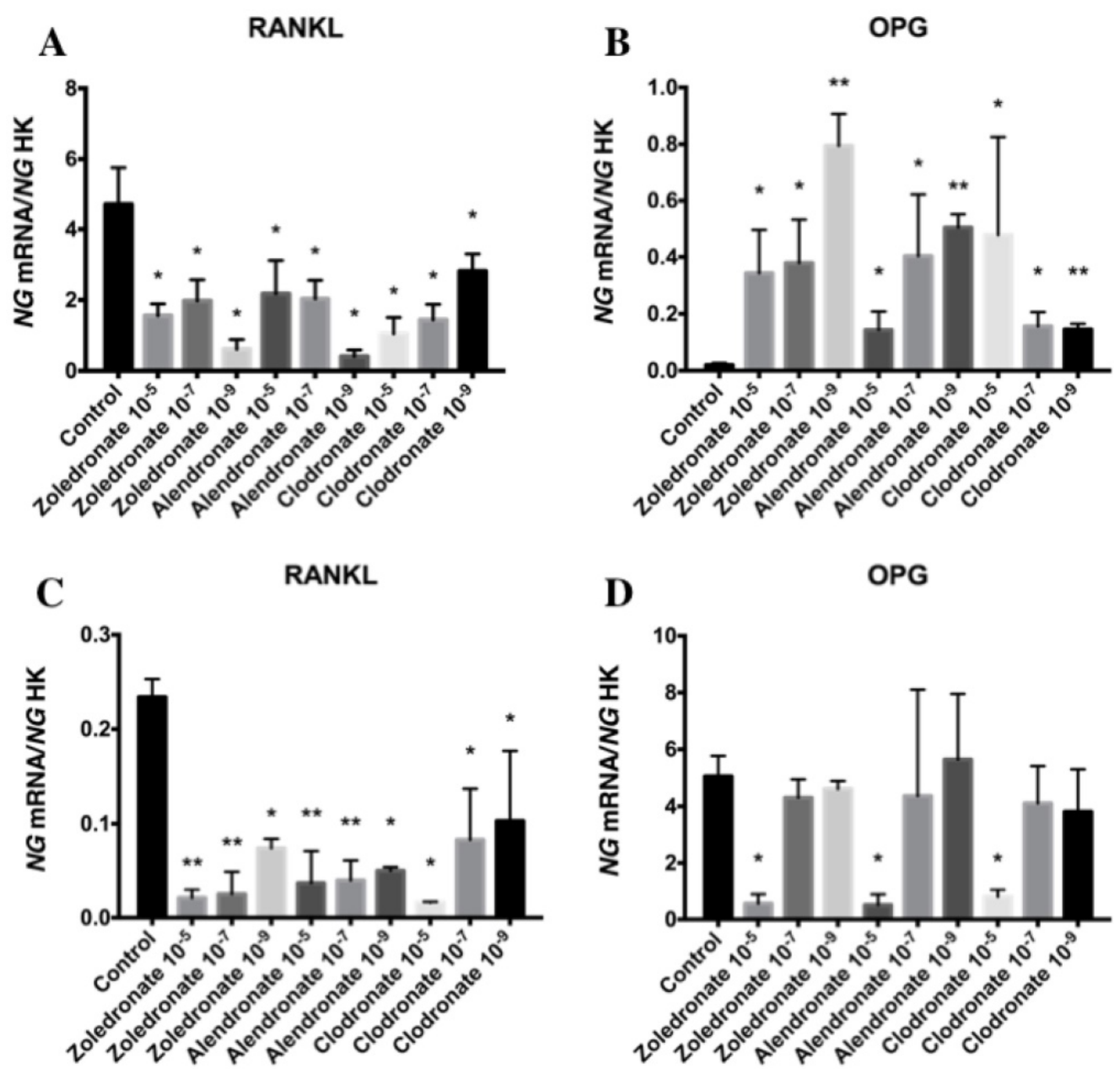

Figure 2. Expression of osteoblast genes (RANKL and OPG) treated for $24 \mathrm{~h}$ with zoledronate, alendronate or clodronate at doses of 10-5, 10-7, or 10-9 M. MG-63 cell line (A,B); HOB (C,D). Data are expressed as ng of mRNA per average ng of housekeeping mRNAs \pm SD. $* \mathrm{p}<0.05$, **p $<0.001$
Runx2, ALP, Col-I, OSX, and OSC. Treatment with each NP for $24 \mathrm{~h}$ reduced the expression of all of these genes, more markedly at the lowest doses $\left(10^{-7}\right.$ and $\left.10^{-9} \mathrm{M}\right)$. No differences in these results were observed between HOB and MG-63 cell lines.

\section{Effect of BPs on gene expression of BMP-2, BMP-7 and VEGF}

Figure 5 exhibits the q-RT-PCR results for the gene expression of BMP-2, BMP-7, and VEGF. In both cell lines, $24 \mathrm{~h}$ of treatment with each BP significantly reduced the expression of BMP-2 and BMP-7, with a more marked reduction at the lowest dose $\left(10^{-9} \mathrm{M}\right)$, and significantly increased the expression of VEGF versus controls at $10^{-7}$ and, more markedly, at $10^{-9} \mathrm{M}$.

\section{Discussion}

The results of this study demonstrate that the BPs zoledronate, alendronate, and clodronate can modulate the expression of genes involved in osteoblast growth and maturation and in osteoblast-osteocla st interaction (RANKL-OPG). In general, low doses of these drugs increased the gene expression of important

molecules for osteoblast growth (TGF- $\beta 1$, TGF- $\beta$ R1, TGF- $\beta$ R2,

TGF- $\beta R 3$, and VEGF) and decreased the gene expression of molecules directly related to cell maturation

(RUNX-2, Col-1, OSX, OSC, BMP-2, BMP-7, or ALP).

The TGF- $\beta$ superfamily comprises more than 40 members, including TGF- $\beta$ s, Nodal, Activin, and BMPs [21]. TGF- $\beta$ signaling is critical for the regulation of osteoblast differentiation and 
bone formation, and signaling relays in each stage are responsible for the final target gene expression [22, 23]. At low to moderately elevated levels, TGF$\beta 1$ was reported to stimulate early osteoblast proliferation but inhibit terminal differentiation and mineralization [24-27]. Furthermore, the inhibition of TGF- $\beta 1$ signaling has been found to increase bone mass and improve bone quality [24, 27, 28]. Animal studies showed that a reduction in TGF- $\beta 1$ signaling enhanced bone stiffness in the 3-point bending test $[24,29,30]$ and that inhibition of TGF- $\beta 1$ type I receptor kinase had anabolic and anticatabolic effects on bone, increasing both the mineral density and stiffness of bone [28]. According to the above data, TGF- $\beta 1$ signaling has detrimental effects on bone quality. In the present study, the expression of TGF- $\beta 1$ and its receptors was significantly increased after BP treatment at low doses $\left(10^{-7}\right.$ and $\left.10^{-9} \mathrm{M}\right)$, confirming previous reports that low $\mathrm{BP}$ doses increase the proliferation of osteoblasts and decrease their differentiation capacity [6, 7]. Taken together, these data indicate a relationship between the effect of BPs on osteoblasts and the development of BRONJ. In agreement with our findings, it was previously observed that treatment of osteoblasts with low doses of alendronate produced an early increase in their TGF- $\beta 1 /$ Smad3 expression, which may contribute to the bone-preserving effects of BPs by maintaining osteoblast proliferation [31-33]. TGF- $\beta 1$ is also involved in the synthesis of RANKL, a member of the tumor necrosis factor (TNF) superfamily, which is produced and secreted by osteoblasts. RANKL stimulates osteoclasts via its receptor RANK, a membrane-bound protein present in osteoclasts and their precursors. The interaction between RANKL and RANK can be inhibited by OPG, a soluble protein also produced by osteoblasts [34-36]. TGF- $\beta 1$ is known to enhance matrix production and osteoblast differentiation while reducing the ability of osteoblasts to secrete RANKL; hence, TGF- $\beta 1$ indirectly limits further osteoclast formation and may reduce bone mass. According to the present results, $\mathrm{BP}$ treatment of osteoblasts leads to a reduction in their RANKL expression, which is probably related to the increased expression of TGF- $\beta 1$. In contrast, the effects on OPG expression differed between the cell lines, and a significant post-treatment increase was only observed in MG-63 cells. Our results suggest that $\mathrm{BP}$ treatment of osteoblasts may severely alter the RANKL-OPG complex, which would reduce bone resorption and turnover, giving rise to the accumulation of non-renewed and hypermineralized bone.
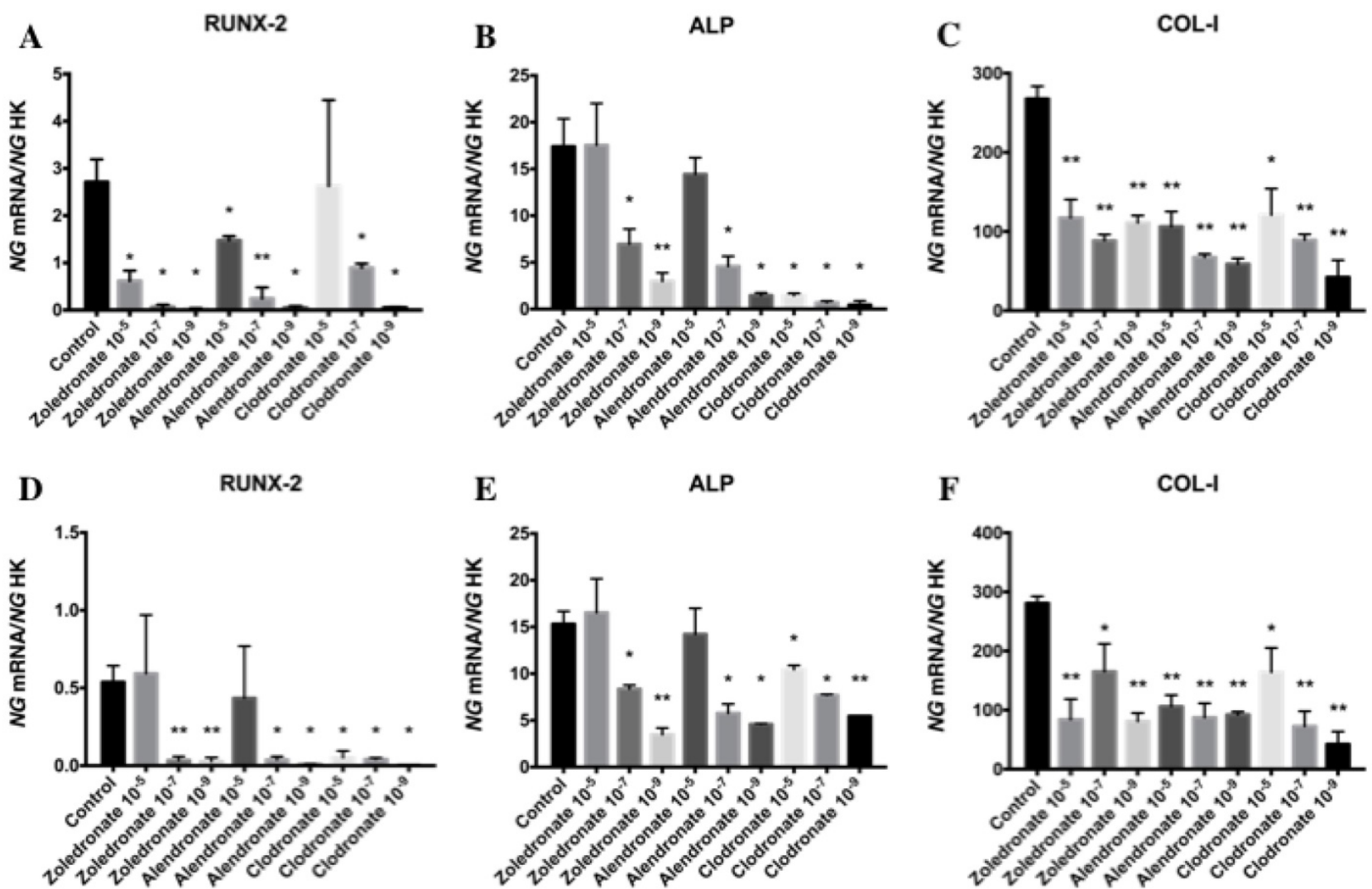

Figure 3. Expression of osteoblast genes (RUNX-2, ALP and Col-I) treated for $24 \mathrm{~h}$ with zoledronate, alendronate or clodronate at doses of 10-5, 10-7, or 10-9 M. MG-63 cell line (A,B,C); HOB (D,E,F). Data are expressed as ng of mRNA per average ng of housekeeping $m R N A s \pm S D$. Data are expressed as ng of $m R N A$ per average $n g$ of housekeeping mRNAs \pm SD. ${ }^{*} p<0.05$, **p $<0.001$ 

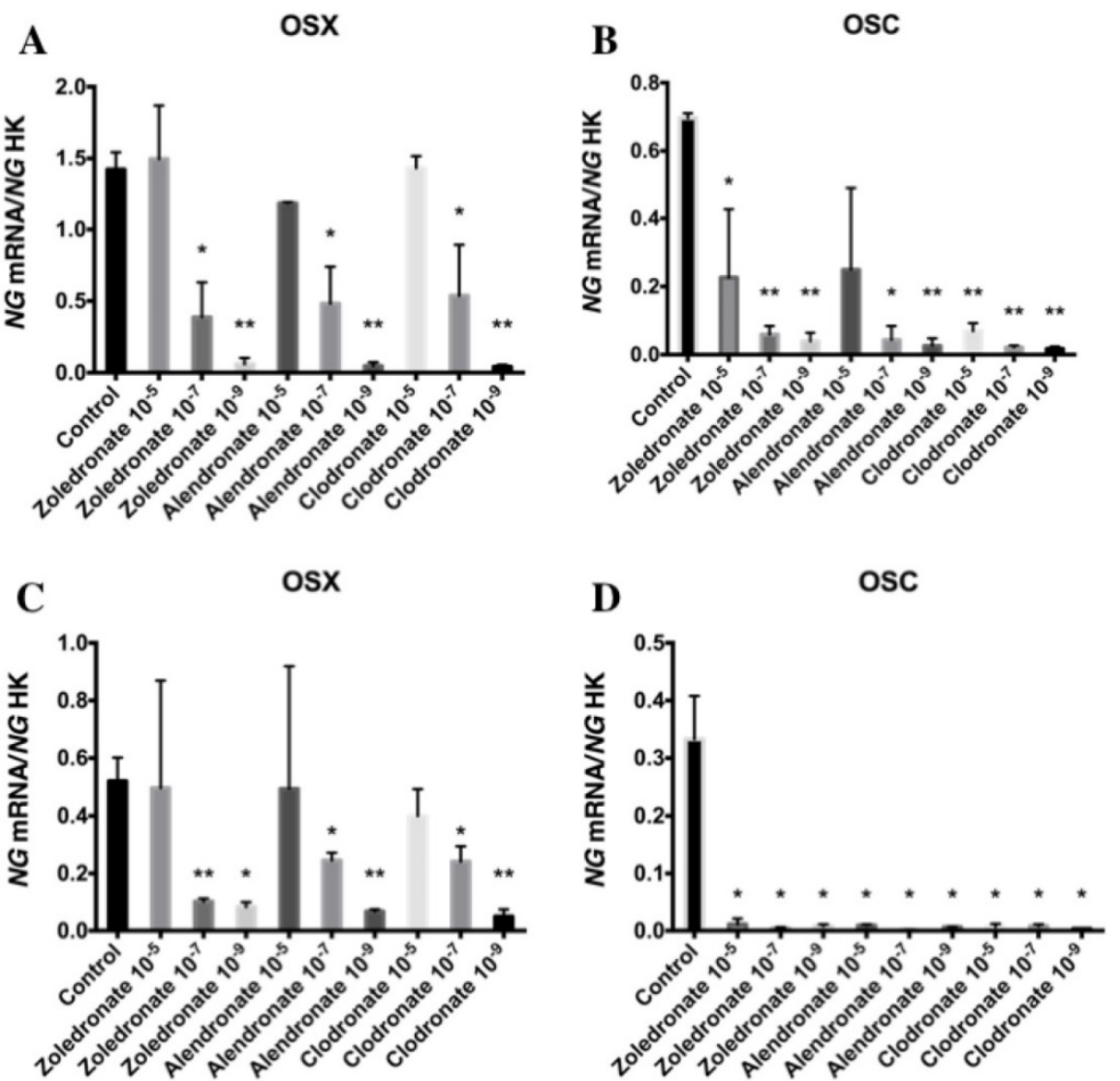

Figure 4. Expression of osteoblast genes (OSX and OSC) treated for $24 \mathrm{~h}$ with zoledronate, alendronate or clodronate at doses of 10-5, 10-7, or 10-9 M. MG-63 cell line $(\mathbf{A}, \mathbf{B}) ; \mathrm{HOB}(\mathbf{C}, \mathbf{D})$. Data are expressed as ng of mRNA per average $n g$ of housekeeping mRNAs $\pm \mathrm{SD}$. ${ }^{*} \mathrm{p}<0.05,{ }^{* *} \mathrm{p}<0.001$

$\mathbf{A}$

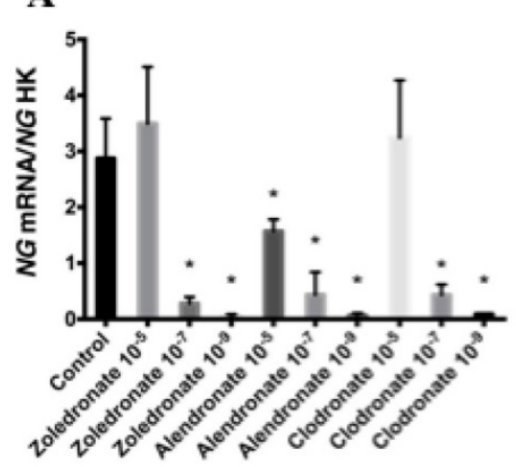

D

BMP2

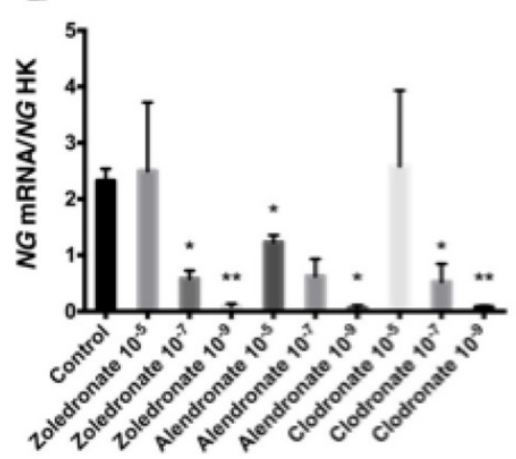

B

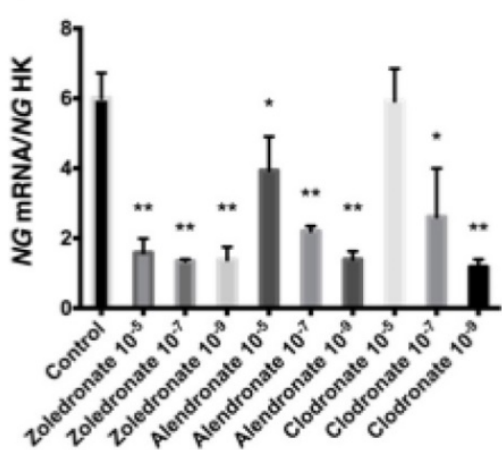

E

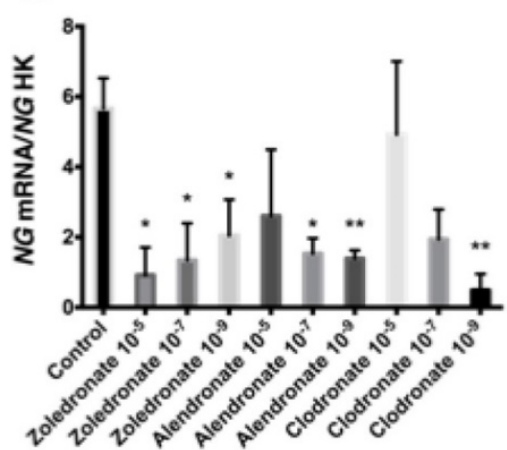

C VEGF

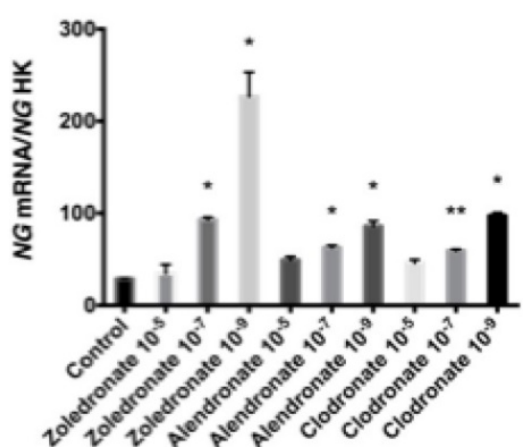

F VEGF

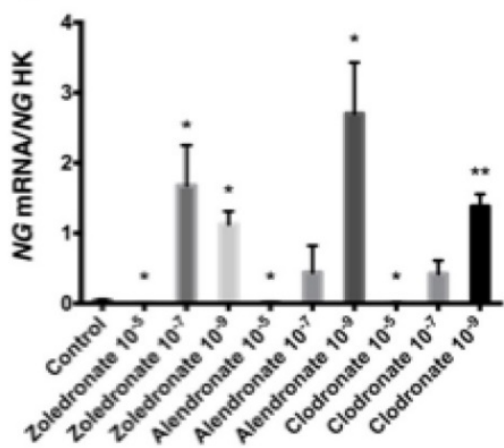

Figure 5. Expression of osteoblast genes (BMP-2, BMP-7 and VEGF) treated for $24 \mathrm{~h}$ with zoledronate, alendronate or clodronate at doses of 10-5, 10-7, or 10-9 M. MG-63 cell line (A,B,C); HOB (D,E,F). Data are expressed as ng of mRNA per average ng of housekeeping mRNAs \pm SD. ${ }^{*} p<0.05, *^{*} \mathrm{p}<0.001$ 
The differentiation/maturation of osteoblastic cells follows a linear succession from osteoprogenitors to preosteoblasts, osteoblasts, and osteocytes. Osteoblasts pass through three functional stages in vivo and in vitro: proliferation, bone matrix synthesis/maturation, and mineralization. The membrane expression of specific function-related proteins (markers) has been observed on precursor cells during their differentiation [37, 38]. In the present study, low-dose BP treatment reduced the expression of BMP-2 and BMP-7. BMP-2 plays a major role in bone formation/remodeling and development and in osteoblast differentiation [39], inducing the expression of ALP and other osteoblastic markers and promoting calcium mineralization [40, 41]. The reduced expression of genes encoding these proteins would help to explain our previous observations on the capacity of BPs to inhibit osteoblast differentiation $[6,7]$.

Runx-2 is the prime marker of osteoblast differentiation. TGF- $\beta 1$ represses RUNX-2 expression through Smad3 to control extracellular matrix elastic modulus, a key determinant of bone material properties [24, 42]. Col-I and ALP expression is observed in the early stage of osteoblast differentiation and persists in early and mature osteoblasts [43]. Another essential transcription factor for osteoblast differentiation and bone formation is OSX, whose expression implies the loss of bipotentiality from preosteoblast to osteoblast and chondrocyte [44]. Our treatment of osteoblasts with low BP doses produced a significant reduction in the gene expression of these early differentiation markers. This treatment also reduced the expression by osteoblasts of OSC, a late differentiation marker, which appears at the start of mineralization and is an osteogenic marker of the final stages of osteoblast differentiation [43,45-47].

Osteonecrosis of the jaw related to alterations in angiogenesis was recently described in cancer patients treated with bevacizumab, an anti-angiogenic agent that inhibits VEGF, leading the American Association of Oral and Maxillofacial Surgeons (AAOMS) to update the term "BRONJ" to "medication-related osteonecrosis of the jaw" (MRONJ)[48]. The expression and production of pro-angiogenic factors such as VEGF and angiopoietin (ANG), which affect endothelial cell growth, migration, and vessel formation in many tissues, also play an important role in regulating vascular growth in the skeleton $[49,50]$. These factors are produced by osteoblasts and osteocytes, among other bone cells [51,52]. Although some authors have reported reduced VEGF expression in BP-treated osteoblasts [53, 54], we observed a significant increase in VEGF production after $24 \mathrm{~h}$ of treatment with low BP doses, which may be related to the increased TGF- $\beta$ expression observed. Thus, it was recently reported that TGF- $\beta 1$ stimulates VEGF synthesis in osteoblast-like MC3T3-E1 cells via Smad-independent pathways, including p38 mitogen-activated protein (MAP) kinase, p44/p42 MAP kinase, and stress-activated protein kinase/c-Jun N-terminal kinase (SAPK/JNK) pathways, [55, 56].

These data and previous reports demonstrate the importance of dosage in the effect of BPs on osteoblasts [4-7]. Thus, low doses increase the proliferation and reduce the differentiation capacity of osteoblasts [6, 7]; whereas high doses lead their death by apoptosis [5]. Although therapeutic doses of BPs are low, high concentrations can accumulate in bone over long-term treatments but are inactivated by binding with hydroxyapatite; hence, medium acidification from infection can favor a new release and activation of $\mathrm{BP}$ that remains bound to hydroxyapatite crystals [57, 58], with the aforementioned consequences.

Within the limitations of an in vitro study, the results of gene expression in this study are relevant, although it would be interesting to perform more studies to show the effect of bisphosphonates on the protein expression of the genes studied.

In conclusion, the results of this in vitro study of HOBS and MG-63 cell lines indicate that low BP doses can significantly affect the expression of genes essential for osteoblast growth and differentiation and of genes involved in regulating osteoblast-osteoclast interaction, possibly by increasing TGF- $\beta 1$ production. These findings suggest that osteoblasts may play an important role in BRONJ development, without ruling out other factors.

\section{Competing Interests}

The authors have declared that no competing interest exists.

\section{References}

1. Fleisch H. Bisphosphonates: mechanisms of action. Endocr Rev. 1998; 19:80-100.

2. Marx RE. A decade of bisphosphonate bone complications: what it has taught us about bone physiology. Int J Oral Maxillofac Implants. 2014; 29:e247-58.

3. Marx RE. Pamidronate (Aredia) and zoledronate (Zometa) induced avascular necrosis of the jaws: a growing epidemic. J Oral Maxillofac Surg. 2003; 61:1115-7.

4. Walter C, Pabst A, Ziebart T, et al. Bisphosphonates affect migration ability and cell viability of HUVEC, fibroblasts and osteoblasts in vitro. Oral Dis. 2011; 17:194-9.

5. Manzano-Moreno FJ, Ramos-Torrecillas J, De Luna-Bertos E, et al. High doses of bisphosphonates reduce osteoblast-like cell proliferation by arresting the cell cycle and inducing apoptosis. J Cranio-Maxillo-fac Surg. 2015; 43:396-01.

6. Manzano-Moreno FJ, Ramos-Torrecillas J, De Luna-Bertos E, et al. Effect of Clodronate on Antigenic Profile, Growth, and Differentiation of Osteoblast-Like Cells. J Oral Maxillofac Surg. 2016; 74:1765-70.

7. Manzano-Moreno FJ, Ramos-Torrecillas J, De Luna-Bertos E, et al. Nitrogen-containing bisphosphonates modulate the antigenic profile and inhibit the maturation and biomineralization potential of osteoblast-like cells. Clin Oral Investig. 2015; 19:895-02 
8. Frith JC, Mönkkönen J, Auriola S, et al. The molecular mechanism of action of the antiresorptive and antiinflammatory drug clodronate: evidence for the formation in vivo of a metabolite that inhibits bone resorption and causes osteoclast and macrophage apoptosis. Arthritis Rheum. 2011; 44:2201-10.

9. Marx RE, Cillo JE Jr, Ulloa JJ. Oral bisphosphonate-induced osteonecrosis: risk factors, prediction of risk using serum CTX testing, prevention, and treatment. J Oral Maxillofac Surg. 2007; 65:2397-10.

10. Ruggiero SL, Dodson TB, Assael LA, et al. American Association of Oral and Maxillofacial Surgeons position paper on bisphosphonate-related osteonecrosis of the jaws--2009 update. J Oral Maxillofac Surg. 2009; 67:2-12.

11. Florencio-Silva R, Sasso GR da S, Sasso-Cerri E, et al. Biology of Bone Tissue: Structure, Function, and Factors That Influence Bone Cells. BioMed Res Int. 2015; 421746.

12. Xiong Y, Yang HJ, Feng J, et al. Effects of alendronate on the proliferation and osteogenic differentiation of MG-63 cells. J Int Med Res. 2009; 37:407-16.

13. Oursler MJ. Osteoclast synthesis and secretion and activation of latent transforming growth factor beta. J Bone Miner Res. 1994; 9:443-52.

14. Tang $\mathrm{Y}, \mathrm{Wu} \mathrm{X}$, Lei $\mathrm{W}$, et al. TGF-beta1-induced migration of bone mesenchymal stem cells couples bone resorption with formation. Nat Med. 2009; 15:757-65.

15. Atfi A, Baron R. PTH battles TGF-beta in bone. Nat Cell Biol. 2010; 12:205-7.

16. Davis J, Tucci M, Franklin L, et al. The effects of growth factors on the production of osteopontin and osteocalcin. Biomed Sci Instrum. 2006; 42:31-6.

17. Reyes-Botella C, Montes MJ, Vallecillo-Capilla MF, et al. Expression of molecules involved in antigen presentation and $\mathrm{T}$ cell activation (HLA-DR, CD80, CD86, CD44 and CD54) by cultured human osteoblasts. J Periodontol. 2000; 71:614-7.

18. García-Martínez O, Reyes-Botella C, Díaz-Rodríguez L, et al. Effect of Platelet-Rich Plasma on Growth and Antigenic Profile of Human Osteoblasts and Its Clinical Impact. J Oral Maxillofac Surg. 2012; 70:1558-64.

19. Vandesompele J, De Preter K, Pattyn F, et al. Accurate normalization of real-time quantitative RT-PCR data by geometric averaging of multiple internal control genes. Genome Biol . 2002; 3:RESEARCH0034.

20. Ragni E, Viganò M, Rebulla P, et al. What is beyond a qRT-PCR study on mesenchymal stem cell differentiation properties: how to choose the most reliable housekeeping genes. J Cell Mol Med. 2013; 17:168-80.

21. Guo X, Wang X-F. Signaling cross-talk between TGF-beta/BMP and other pathways. Cell Res. 2009; 19:71-88.

22. Chen G, Deng C, Li Y-P. TGF- $\beta$ and BMP signaling in osteoblast differentiation and bone formation. Int J Biol Sci. 2012; 8:272-88.

23. Manzano-Moreno FJ, Medina-Huertas R, Ramos-Torrecillas J, et al. The effect of low-level diode laser therapy on early differentiation of osteoblast via BMP-2/TGF- $\beta 1$ and its receptors. J Cranio-Maxillo-fac Surg. 2015; 43:1926-32.

24. Balooch G, Balooch M, Nalla RK, et al. TGF-beta regulates the mechanical properties and composition of bone matrix. Proc Natl Acad Sci U S A. 2005; 102:18813-18.

25. Lieb E, Vogel T, Milz S, et al. Effects of transforming growth factor beta1 on bonelike tissue formation in three-dimensional cell culture. II: Osteoblastic differentiation. Tissue Eng. 2004; 10:1414-25.

26. Breen EC, Ignotz RA, McCabe L, et al. TGF beta alters growth and differentiation related gene expression in proliferating osteoblasts in vitro, preventing development of the mature bone phenotype. J Cell Physiol. 1994; 160:323-35.

27. Borton AJ, Frederick JP, Datto MB, et al. The loss of Smad3 results in a lower rate of bone formation and osteopenia through dysregulation of osteoblast differentiation and apoptosis. J Bone Miner Res. 2001; 16:1754-64.

28. Mohammad KS, Chen CG, Balooch G, et al. Pharmacologic inhibition of the TGF-beta type I receptor kinase has anabolic and anti-catabolic effects on bone. PloS One. 2009; 4:e5275.

29. Chang JL, Brauer DS, Johnson J, et al. Tissue-specific calibration of extracellular matrix material properties by transforming growth factor- $\beta$ and Runx2 in bone is required for hearing. EMBO Rep. 2010; 11:765-71.

30. Edwards JR, Nyman JS, Lwin ST, et al. Inhibition of TGF- $\beta$ signaling by $1 D 11$ antibody treatment increases bone mass and quality in vivo. J Bone Miner Res. 2010; 25:2419-26.

31. Fromigué O, Body JJ. Bisphosphonates influence the proliferation and the maturation of normal human osteoblasts. J Endocrinol Invest. 2002; 25:539-46.

32. Pan B, To LB, Farrugia AN, et al. The nitrogen-containing bisphosphonate, zoledronic acid, increases mineralisation of human bone-derived cells in vitro. Bone. 2004; 34:112-23.

33. Reinholz GG, Getz B, Pederson L, et al. Bisphosphonates directly regulate cell proliferation, differentiation, and gene expression in human osteoblasts. Cancer Res. 2000; 60:6001-7.

34. Yasuda H, Shima N, Nakagawa N, et al. Identity of osteoclastogenesis inhibitory factor (OCIF) and osteoprotegerin (OPG): a mechanism by which OPG/OCIF inhibits osteoclastogenesis in vitro. Endocrinology. 1998; 139:1329-37.

35. Burgess TL, Qian Y, Kaufman S, et al. The ligand for osteoprotegerin (OPGL) directly activates mature osteoclasts. J Cell Biol. 1999; 145:527-38.

36. Lin JM, Callon KE, Lin CQ, et al. Alteration of bone cell function by RANKL and OPG in different in vitro models. Eur J Clin Invest. 2007; 37:407-15.

37. Liu F, Malaval L, Gupta AK, Aubin JE. Simultaneous detection of multiple bone-related mRNAs and protein expression during osteoblast differentiation: polymerase chain reaction and immunocytochemical studies at the single cell level. Dev Biol. 1994; 166:220-34.
38. Malaval L, Modrowski D, Gupta AK, Aubin JE. Cellular expression of bone-related proteins during in vitro osteogenesis in rat bone marrow stromal cell cultures. J Cell Physiol. 1994;158:555-72.

39. Li X, Cao X. BMP signaling and skeletogenesis. Ann N Y Acad Sci. 2006; 1068:26-40.

40. Gu K, Zhang L, Jin T, Rutherford RB. Identification of potential modifiers of Runx2/Cbfa1 activity in $\mathrm{C} 2 \mathrm{C} 12$ cells in response to bone morphogenetic protein-7. Cells Tissues Organs. 2004; 176:28-40.

41. Shen B, Wei A, Whittaker S, et al. The role of BMP-7 in chondrogenic and osteogenic differentiation of human bone marrow multipotent mesenchymal tromal cells in vitro. J Cell Biochem. 2010; 109:406-16.

42. Jia J, Yao W, Amugongo S, et al. Prolonged alendronate treatment prevents the decline in serum TGF- $\beta 1$ levels and reduces cortical bone strength in long-term estrogen deficiency rat model. Bone. 2013; 52:424-32.

43. Sims NA, Vrahnas C. Regulation of cortical and trabecular bone mass by communication between osteoblasts, osteocytes and osteoclasts. Arch Biochem Biophys. 2014; 561C:22-28.

44. Nakashima K, Zhou X, Kunkel G, et al. The novel zinc finger-containing transcription factor osterix is required for osteoblast differentiation and bone formation. Cell. 2002; 108:17-29.

45. Tsuboi K, Hasegawa T, Yamamoto T, et al. Effects of drug discontinuation after short-term daily alendronate administration on osteoblasts and osteocytes in mice. Histochem Cell Biol. 2016; 146:337-50.

46. Krüger TB, Herlofson $\mathrm{BB}$, Landin MA, Reseland JE. Alendronate alters osteoblast activities. Acta Odontol Scand. 2016; 74:550-57.

47. Zafar S, Coates DE, Cullinan MP, et al. Effects of zoledronic acid and geranylgeraniol on the cellular behaviour and gene expression of primary human alveolar osteoblasts. Clin Oral Investig. 2016; 20:2023-35.

48. Ruggiero SL, Dodson TB, Fantasia J, et al. American Association of Oral and Maxillofacial Surgeons position paper on medication-related osteonecrosis of the jaw--2014 update. J Oral Maxillofac Surg. 2014; 72:1938-56.

49. Portal-Núñez S, Lozano D, Esbrit P. Role of angiogenesis on bone formation. Histol Histopathol. 2012; 27:559-66.

50. Street J, Lenehan B. Vascular endothelial growth factor regulates osteoblast survival - evidence for an autocrine feedback mechanism. J Orthop Surg. 2009; 4:19.

51. Horner A, Bord S, Kelsall AW, et al. Tie2 ligands angiopoietin-1 and angiopoietin-2 are coexpressed with vascular endothelial cell growth factor in growing human bone. Bone. 2001; 28:65-71.

52. Saadeh PB, Mehrara BJ, Steinbrech DS, et al. Transforming growth factor-beta1 modulates the expression of vascular endothelial growth factor by osteoblasts. Am J Physiol. 1999; 277:C628-37.

53. Ishtiaq S, Edwards S, Sankaralingam A, et al. The effect of nitrogen containing bisphosphonates, zoledronate and alendronate, on the production of pro-angiogenic factors by osteoblastic cells. Cytokine. 2015; 71:154-60.

54. Yoshida M, Tokuda H, Ishisaki A, et al. Tiludronate inhibits prostaglandin F2alpha-induced vascular endothelial growth factor synthesis in osteoblasts. Mol Cell Endocrinol. 2005; 236:59-66.

55. Kuroyanagi G, Otsuka $\mathrm{T}$, Yamamoto $\mathrm{N}$, et al. Resveratrol suppresses TGF- $\beta$-induced VEGF synthesis in osteoblasts: Inhibition of the p44/p42 MAPKs and SAPK/JNK pathways. Exp Ther Med. 2015; 9:2303-10.

56. Tokuda H, Hatakeyama D, Akamatsu S, et al. Involvement of MAP kinases in TGF-beta-stimulated vascular endothelial growth factor synthesis in osteoblasts. Arch Biochem Biophys. 2003; 415:117-25.

57. Otto S, Hafner S, Mast G, et al. Bisphosphonate-related osteonecrosis of the jaw: is $\mathrm{pH}$ the missing part in the pathogenesis puzzle? J Oral Maxillofac Surg. 2010; 68:1158-61.

58. Otto S, Pautke C, Opelz C, et al. Osteonecrosis of the jaw: effect of bisphosphonate type, local concentration, and acidic milieu on the pathomechanism. J Oral Maxillofac Surg. 2010; 68:2837-45. 